\title{
Changes in heart rate recovery index after a programme of strength/endurance training in hypoxia
}

\author{
Jesús Álvarez-Herms ${ }^{a}$, Sonia Julià-Sánchez ${ }^{a}$, Francisco Corbi ${ }^{b}$, Teresa Pagès ${ }^{a}$, \\ Ginés Viscor ${ }^{\mathrm{a}, *}$ \\ a Departamento de Fisiología e Inmunología, Facultad de Biologia, Universidad de Barcelona, Barcelona, Spain \\ ${ }^{\mathrm{b}}$ Instituto Nacional de Educación Física de Catalunya (INEFC), Centro de Lleida - Universidad de Lleida (UdL), Lleida, Spain
}

Received 22 June 2011; accepted 21 July 2011

Available online 22 September 2011

\section{KEYWORDS}

Hypoxia;

Heart rate;

Strength training

\section{PALABRAS CLAVE}

Hipoxia;

frecuencia cardiaca;

entrenamiento de

fuerza resistencia

\begin{abstract}
Objective: To determine whether twelve sessions of resistance training on lower limbs at simulated altitude $(2500 \mathrm{~m})$ were efficient to elicit an improvement in heart rate recovery index in the first $3 \mathrm{~min}$ of recovery after a maximal jump test.

Materials and methods: Twelve young physically active subjects were divided in two balanced groups for training in hypoxia (HYP) and normal oxygen (NOR). The subjects were assigned to each group based on previous test results in the $60 \mathrm{~s}$ counter-movement jump test (CMJ60).

Results: Both groups performed identical strength training (volume, intensity, character and effort conditions) on the lower limbs (squats, half-squats and jumps) for 4 weeks. Both groups improved the measured parameters in all cases. We analyzed the time course of heart rate during the CMJ60 test and the subsequent 3 min recovery period. HYP group $(n=5)$ improved the heart rate recovery index as compared to NOR group (Student's $t$-test) at minute $2(P=0.03)$ and minute $3(P=0.05)$.

Conclusions: We conclude that a protocol of resistance training on lower limbs (12 sessions in 4 weeks) at a simulated altitude could improve heart rate recovery index compared to the same training performed at sea level.

(c) 2011 Consell Català de l'Esport. Generalitat de Catalunya. Published by Elsevier España, S.L. All rights reserved.
\end{abstract}

Valoración de la Frecuencia Cardíaca de Recuperación después de un programa
de entrenamiento de fuerza resistencia en hipoxia

Resumen

Objetivo: Doce sujetos jóvenes físicamente activos se dividieron en dos grupos equilibrados para entrenar en hipoxia (HYP) y normoxia (NOR).

\footnotetext{
* Corresponding author.

E-mail address: gviscor@ub.edu (G. Viscor).
} 
Material y métodos: Los sujetos fueron asignados a cada grupo en base a los resultados en una prueba previa de salto en contramovimiento de sesenta segundos (CMJ60). Ambos grupos realizaron durante 4 semanas un entrenamiento idéntico de fuerza (volumen, intensidad, carácter y condiciones de esfuerzo) en las extremidades inferiores (squat, half-squat y saltos). Resultados: Ambos grupos mejoraron en todos los casos. Se analizó la evolución temporal de la frecuencia cardiaca durante la prueba CMJ60 y el posterior período de recuperación de tres minutos. El grupo HYP $(n=5)$ refleja una mejoría del índice de recuperación de la frecuencia cardiaca en comparación con el grupo NOR (prueba t de Student) después de $2(p=0,03)$ y 3 $(p=0,05)$ minutos de finalizar el test de saltos.

Conclusiones: Concluimos que un protocolo de entrenamiento de fuerza resistencia ( 12 sesiones en 4 semanas) de las extremidades inferiores en altitud simulada podría mejorar el índice de recuperación de la frecuencia cardiaca en comparación con el mismo entrenamiento realizado a nivel del mar.

(C) 2011 Consell Català de l'Esport. Generalitat de Catalunya. Publicado por Elsevier España, S.L. Todos los derechos reservados.

\section{Introduction}

Monitoring the evolution of heart rate in the recovery phase after physical exertion is a simple and non-invasive method for assessing the cardiovascular health and physical condition of subjects. ${ }^{1,2}$ A direct relationship has been reported between a more rapid decline from maximum heart rate to values below 130 beats per minute and improved cardiovascular adaptation. ${ }^{3}$ This improvement has been associated with various internal physiological adjustments in such a way that a lower heart rate in the recovery phase would be due to decreased venous return and systemic needs. ${ }^{4}$ The increase in heart rate in response to exercise is accompanied by a reduction in vagal tone that is further increased over basal level after exercise has ended ${ }^{5}$ through the activation of the autonomic nervous system immediately after cessation of maximum activity. ${ }^{6}$

In addition to its use to evaluate physical condition, heart rate recovery (HRR) from maximal exercise in the first few minutes after ceasing the activity is also a valid indicator of risk of sudden death during exercise. ${ }^{7}$ Given the relatively large number of cases and the notoriety of this type of death, HRR monitoring has gained importance as a useful non-invasive tool to evaluate cardiovascular health and fitness. $^{8}$

To the best of our knowledge, no previous studies have analyzed or evaluated the evolution of HRR following a protocol of simulated altitude strength endurance training on lower limbs, neither has the impact of training stimulus on the cardiovascular system been addressed.

Scientific research on the benefits of training and acute, chronic or intermittent exposure to hypoxia is extensive in real and simulated altitude conditions. ${ }^{9,10}$ Interest in this topic was aroused because of the excellent results in endurance events (with predominant aerobic metabolism) achieved by African athletes residing at moderate altitudes. ${ }^{11}$ It was the incursion of these athletes at the 1968 Mexico Olympics, and their subsequent overwhelming dominance in these events that spurred studies into finding explanations for these quantitative differences in physical performance. ${ }^{12,13}$
Altitude training (real or simulated) is widely reported to favour aerobic performance, ${ }^{9,10}$ but there is also some evidence of improved anaerobic capacity. ${ }^{14-16}$ Hypoxic training has become available to more people in recent years through altitude chambers (hypobaric hypoxia) and hypoxic tents (normobaric hypoxia). No health risks have been associated with these practices. ${ }^{17}$

Haematological changes and muscular adaptations are the main benefits of time spent at moderate altitude, ${ }^{18,19}$ thus increasing performance. The increase in red cell mass, and subsequently in oxygen transport and aerobic capacity, ${ }^{20}$ and the improved specific adaptations of skeletal muscle to the hypoxic environment could also favour anaerobic endurance $^{21}$ since enhanced anaerobic metabolism at rest may increase buffer capacity and clearance of lactate from the muscle. ${ }^{22}$

Here we studied the response of the cardiovascular system after a maximal anaerobic test following a protocol of lower limb resistance training under an intermittent simulated altitude exposure programme. We evaluated the decrease in heart rate for $3 \mathrm{~min}$ after the end of the test. Tests comprised a 60-s continuous countermovement jump ${ }^{23,24}$ and was conducted at sea level. HRR was considered an indicator of improved fitness. The heart rate recovery index (HRRI) was calculated by applying the formula described by Lamiel-Luengo. ${ }^{1,3}$

\section{Materials and methods}

The design of this study resembles that of a clinical trial. The training programme was conducted at two centres. Subjects were aged between 19 and 33 years of age (see Table 1).

Table 1 Antropometric data from subjects $(n=12)$.

\begin{tabular}{lr}
\hline Age (years) & $24.1 \pm 4.21$ \\
Height $(\mathrm{cm})$ & $174.3 \pm 7.47$ \\
Body mass $(\mathrm{kg})$ & $68.9 \pm 7.4$ \\
Body mass index & $22.4 \pm 1.81$ \\
\hline
\end{tabular}


All were physical education students or teachers that did not practice elite sport but were in an acceptable physical condition. All were non-smokers and were presumably healthy. All subjects voluntarily consented to participate in the study. Subjects attended two informative sessions prior to the start of the study. During the first they were informed about the objectives of the study, the nature and risks of the training and the evaluation tests to be applied. The study was designed in accordance with the ethical standards of the University of Barcelona's Ethical Committee and the principles of the Helsinki Declaration of 1975, revised in 1983. In the second session subjects were familiarized with the training procedures. On the basis of the results of the initial test (PRE), they were assigned to the hypoxia (HYP, $n=5$ ) or normoxia (NOR, $n=7$ ) group in order to homogenise gender and fitness status. ${ }^{6}$ Both groups trained in equal terms of timing and schedule, workload volume and the materials used, with the only difference being exposure to a hypoxic and normoxic environment respectively. All the subjects were subjected to 12 specific training sessions in which the characteristics of the effort were maintained throughout all the programme with a fast execution level but without reaching muscle failure. Each session included additional exercises with compensatory stretching (hamstrings, iliopsoas, quadriceps, lower back, abdomen, etc.). The training protocol for the HYP group was conducted in a hypobaric chamber located on the campus of Bellvitge (Barcelona) at a barometric pressure of $760 \mathrm{hPa}(570 \mathrm{mmHg})$, equivalent to $2500 \mathrm{~m}$ above sea level corresponding to the geographic barometric pressure in most altitude training centres. ${ }^{17,27}$ The NOR group trained in the Montjuïc Centre (Barcelona) of the Catalonia National Institute of Physical Education (INEFC) (75 $\mathrm{m}$ above sea level).

Specific strength training of lower limbs was scheduled with the aim to improve their lactic anaerobic capacity and thus jumping ability and retention time. ${ }^{24,25}$ The training programme included 12 sessions ( 3 days per week; 4 weeks) oriented to specifically train lower extremity strength endurance through half-squats, jump-squats and jumps. All subjects did a standardised warm-up in which they performed 4-5 min of aerobic exercise (mostly static cycling) followed by static stretching and dynamic activity. This was followed by a series of warm-up exercises with a lower work load than those individually prescribed for each training session. The main training was of high intensity (full individually prescribed workload) and designed to be suitable for the nature of the performance assessment test proposed (a series of countermovement jumps for $60 \mathrm{~s}$ ). Workload volume was slightly increased in the first 2 weeks but did not reach the maximal level. The execution speed was controlled and subjects did not lift their heels off the ground. The recovery time between the sets of exercises was incomplete, in order to induce fatigue and muscle accumulation of metabolites (lactate, $\mathrm{H}^{+}$, etc.). The purpose was to improve lactic anaerobic capacity, muscular buffer capacity and blood clearance. This training can be described as a succession of short intense intervals.During the last 2 weeks of the programme, main training was performed at supramaximal intensity but with a marked reduction of the volume in comparison to the first two weeks. The maximum speed of execution was for loaded (week 3) and unloaded (week 4) jumps. Recoveries between series were also longer. The approximate volume was 350-380 repetition/week ((week 1), 500-530 rep/week (week 2), 300-320 $\mathrm{rep} /$ week (week 3) and 200-220 rep/week (week 4). An example of sessions for a representative individual was: Week 1 , A series of 15 repetitions of 3 sets with 1 min of recovery between sets. The whole session consisted of 3 of this series with an intermediate recovery of $6 \mathrm{~min}$. Week 2 , Two series, with $8 \mathrm{~min}$ of intermediate recovery, comprising 4 sets ( 25 repetitions) with $90 \mathrm{~s}$ of recovery between sets. Week 3, 3 series, with 5 min recovery between them, composed of 5 repetitions of 10 sets with $45 \mathrm{~s}$ of recovery between sets. Week 4 , 3 series, with 6 min recovery between them, consisting of 2 sets of 10 jumps with 2 min of recovery between sets.

The material used for training sessions consisted of Olympic bars and free weights. Metronomes were used to control the rhythm of execution and intensity. ${ }^{26}$ The execution speed varied from fast controlled explosive, to fast, following the paradigm of cross training as the most appropriate method for improving jumping ability. ${ }^{25}$

To study changes in lactic anaerobic capacity, a continuous jump test for $60 \mathrm{~s}$ (CMJ60 s) was performed. A contact platform (Chronojump) was used following Bosco's ${ }^{23,24}$ protocol to assess the average height and time in the air of each jump. Heart rate was monitored with standard cardiotachometers (Polar S810i and RS800) during the test and the recovery period and data were transferred via infrared port to a PC. Data were processed with Polar software (Polar Protrainer 5.0). Data were collected from the highest intensity of implementation, and the HRR from maximum heart rate reached at the end of the CMJ60 s test was examined. After ending the tests, the subjects lay immediately on an examination couch and rested for $15 \mathrm{~min}$ until recovery.

To assess the HHR, the following formula was applied ${ }^{3}$ :

$H R R I=\frac{H R_{\max }-H R_{i}}{H R_{\max \text { theor }} / H R_{\max }}$

where $\mathrm{HR}_{\text {max }}$ is the maximum heart rate achieved in the test, $\mathrm{HR}_{\mathrm{i}}$ is the heart beat frequency at $\min 1,2$ and 3 of the recovery period respectively, and $\mathrm{HR}_{\max }$ theor is the theoretical maximum heart rate for each subject using the following calculations: Men: 220 - age in years; and Women: (226 - age in years.

A monitoring form was completed for each subject daily during the training programme. Subjects were asked to conduct a daily check on their waking basal heart rate (waking, resting) for $60 \mathrm{~s}$. Also, in an attempt to associate individual stress perception with the possible effect of training on quantifiable physiological variables, subjects were also asked to provide a subjective analysis of the perception of accumulative fatigue and the feeling of recovery from the previous training session.

\section{Statistical analysis}

The HRRI was compared between the two experimental groups using Student's $t$-test for paired samples (pre-post results into each group) and $t$-test between groups. $P<0.05$ was considered to denote significance. Sample means and standard errors are presented by the acronym $\pm \mathrm{SE}$. 
Table 2 Individual values for body mass and basal (BHR) and peak (PHR) heart rates in normoxia and hypoxia.

\begin{tabular}{|c|c|c|c|c|}
\hline Subject code & Age & Body mass & BHR & PHR \\
\hline \multicolumn{5}{|c|}{ Normoxia group } \\
\hline NOR 1 & 20 & $70.6(-0.8)$ & $81(-6)$ & $182(+1)$ \\
\hline NOR 2 & 24 & $71(-0.4)$ & $77(-6)$ & $179(+11)$ \\
\hline NOR 3 & 24 & $64.6(+0.6)$ & $91(-22)$ & $186(-1)$ \\
\hline NOR 4 & 19 & $61(-1.9)$ & $73(-7)$ & $180(+4)$ \\
\hline NOR 5 & 33 & $74.3(-0.9)$ & $54(-1)$ & $176(-1)$ \\
\hline NOR 6 & 26 & $85.2(-0.8)$ & $71(-13)$ & $175(+7)$ \\
\hline NOR 7 & 25 & $79.0(-0.5)$ & $59(+2)$ & $188(+7)$ \\
\hline NOR mean & $24.4 \pm 4.6$ & $72.2 \pm 8.2$ & $72.3 \pm 12.7$ & $179.8 \pm 4.8$ \\
\hline \multicolumn{5}{|l|}{ Hypoxia group } \\
\hline HYP 1 & 29 & $70.8(0)$ & $46(-4)$ & $149(+13)$ \\
\hline HYP 2 & 24 & $70.2(-0.2)$ & $56(+8)$ & $160(+5)$ \\
\hline HYP 3 & 22 & $59.2(-1.8)$ & $81(-9)$ & $184(-1)$ \\
\hline HYP 4 & 18 & $66(+0.6)$ & $74(-11)$ & $186(-19)$ \\
\hline HYP 5 & 27 & $59.0(+1)$ & $59(-5)$ & $161(+1)$ \\
\hline HYP mean & $24.0 \pm 4.3$ & $65.0 \pm 5.7$ & $63.2 \pm 14.1$ & $168 \pm 16.2$ \\
\hline
\end{tabular}

Values are pre-training, parentheses show the difference at the post-training test.

\section{Results}

The anthropometric data of the subjects participating in the study are shown in Table 1.

Table 2 shows the individual changes in body mass and in the basal and peak heart rates when comparing the two tests performed before and at the end (difference in parenthesis relative to the previous test) of the training programme. Table 3 presents the HRRI values for the first 3 min after completion of the jump test. Table 4 shows the statistical analysis of HRRI data and the corresponding $P$ values and statistical significance (Fig. 1).

\section{Body mass changes}

The NOR group registered a decrease in body weight after the training programme $(1.08 \pm 0.74 \%)$. A reverse trend was found in the HYP group, which showed a slight increase in body weight $(0.5 \pm 1.07 \%)$. However, these differences were not statistically significant.

\section{Basal and peak heart rate values}

With some individual variability, the basal heart rate showed a decrease after the training programme in both groups. In the NOR group a statistically significant $(P=0.045)$ decrease of $-11.5 \%$ from PRE to POST was found, whereas for HYP a non- statistically significant change $(P=0.273)$ of $-5.2 \%$ was detected. Peak heart rate (PHR) in these two groups did not show relevant or statistically significant changes when comparing PRE vs. POST data.

\section{HRRI}

Table 4 shows the statistical significance when comparing HRRI values for PRE and POST training conditions between the NOR and HYP groups (upper panel). No statistical differences in PRE condition was detected between NOR and HYP groups. However, there was a significant improvement in minutes $2(P=0.03)$ and $3(P=0.05)$ in the HYP group in the POST training test in comparison to NOR.

Table 3 Heart rate recovery index (HRRI) for the first 3 min after finishing the test. Values are presented for the normoxia and hypoxia groups. Pre- and post-training protocols.

\begin{tabular}{lcccc}
\hline & \multicolumn{2}{c}{ NOR } & & HYP \\
\cline { 2 - 5 } & Pre & Post & Pre & Post \\
\cline { 2 - 5 } BHR & $72.2 \pm 12.7$ & $64 \pm 6.76$ & $63.2 \pm 14.1$ & $59 \pm 10.2$ \\
PHR & $179.8 \pm 4.8$ & $183.5 \pm 10.21$ & $168.0 \pm 16.2$ & $167.8 \pm 8.8$ \\
HRRI 1 min & $19.7 \pm 0.5$ & $32.55 \pm 6.2$ & $23.8 \pm 7.0$ & $37.4 \pm 7.5$ \\
HRRI 2 min & $35.7 \pm 2.0$ & $45.6 \pm 0.2$ & $33.7 \pm 12.6$ & $63.2 \pm 10.5^{*}$ \\
HRRI 3 min & $43.5 \pm 2.5$ & $56 \pm 2.2$ & $46.88 \pm 14.9$ & $75.6 \pm 14.6 *$ \\
\hline
\end{tabular}

BHR (basal heart rate); PHR (peak heart rate); HHRI 1 min, HHRI 2 min, HHRI 3 min (Heart Rate Recovery index at minutes 1,2 and 3 after completion of the test). NOR: normoxia group; HYP: hypoxia group.

"Statistical significance between NOR and HYP for post-training data. 
Table 4 Statistical analysis (student's $t$-test) between groups on the basis of pre- and post-training data. Statistical (significance (SS) level was taken at $P<0.05$.

\begin{tabular}{|c|c|c|c|c|c|}
\hline \multicolumn{3}{|c|}{$t$-test Pre-training NOR vs HYP } & \multicolumn{3}{|c|}{$t$-test Post-training NOR vs HYP } \\
\hline Time (min) & $P$ value & SS & Time (min) & $P$ value & SS \\
\hline 1 & 0.22 & NO & 1 & 0.38 & NO \\
\hline 2 & 0.46 & NO & 2 & 0.03 & YES \\
\hline 3 & 0.41 & NO & 3 & 0.02 & YES \\
\hline \multicolumn{3}{|c|}{ Paired $t$-test PRE vs POST into normoxia group } & \multicolumn{3}{|c|}{ Paired $t$-test PRE vs POST into hypoxia group } \\
\hline Time (min) & $P$ value & SS & Time $(\min )$ & $P$ value & SS \\
\hline 1 & 0.07 & NO & 1 & 0.04 & YES \\
\hline 2 & 0.01 & YES & 2 & 0.005 & YES \\
\hline 3 & 0.02 & YES & 3 & 0.005 & YES \\
\hline
\end{tabular}

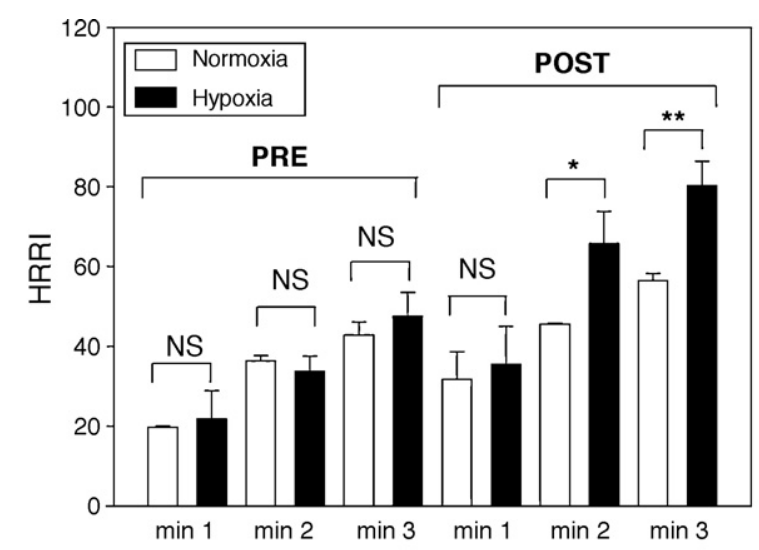

'statistical significances between groups post-training minute 2 ' heart rate recovery Index. $P=0,03$

"s statistical significances between groups post-training minute 3 ' heart rate recovery Index. $P=0,02$

Figure 1 Statistical significances between groups posttraining.

Both (normoxic and hypoxic) training protocols improved the HRRI (lower panel). In the HYP group this enhancement was statistically significant during the first $3 \mathrm{~min}$, but only for minutes 2 and 3 in the NOR group.

\section{Discussion}

The individuals were suitably assigned to the two groups in order to homogenise the sample, as can be seen when examining initial fitness values (comparison of PRE data between the two groups). Furthermore, our strength/endurance training protocol (12 sessions, 4 weeks, 3 days per week) improved the HRRI in NOR and HYP subjects. On the basis of our findings, we conclude that the endurance strength of lower limbs improved in hypoxia and normoxia, thus enhancing the jump capacity for all subjects. However, this improvement was greater for those who trained under hypoxia. Our results indicate that the HRRI of the HYP group was better than that for the control group (NOR). Statistically significant differences were detected between groups at minutes $2(P=0.03)$ and $3(P=0.05)$ post-training. The HYP group showed higher recovery values, reaching almost basal values in minute 3 . This finding indicates improved cardiovascular adaptation to exercise and thus better fitness. $2,7,14$

Altitude training induces greater intensity of the training baseline, particularly during changes of specific muscle enzymes, and thus results in increased run-intensity training. ${ }^{24,26}$ We propose that the improvement in HRRI observed is due to a higher training stimulus at simulated altitude despite applying the same relative intensity workload as at sea level. Thus, with the same degree of effort as at sea level, training in a hypoxic environment increases the intensity of the exercise, both from subjective and from objective points of view. The additional stimulus of hypoxia may elicit more intense adaptive responses at muscular level by increasing the relative intensity of the effort. Thus, according to our findings, a strength/endurance training programme performed in moderate hypoxia could be useful to improve the fitness and HRR of athletes than equal training in normoxia. Therefore, we must consider that sample size was too low to establish definitive conclusions and more studies are needed.

Physical exercise in hypoxia involves a number of cardiovascular changes. There is an increase in resting heart rate and greater hyperventilation in order to compensate for the reduced availability of oxygen. ${ }^{28}$ Thus, at least in part, high intensity exercise does not achieve such high heart rates as at sea level. ${ }^{29}$ Hypoxia directly affects the vascular tone of the pulmonary and systemic resistance vessels and increases ventilation and sympathetic activity via stimulation of peripheral chemoreceptors. ${ }^{30}$ As a result of acute hypoxia, the heart increases its beat rate (both at rest and during exercise), myocardial contractility, and output. The increase in heart rate is directly related to enhanced sympathetic activity and vagal withdrawal. Thus, heart rate is higher at altitude, although the maximum heart rate is reduced compared to normoxia. Enhanced parasympathetic neural activity accounts for the diminished heart rate during exercise. Moreover, during acute hypoxia, epicardial coronary arteries dilate and cardiac contractility increases suddenly. ${ }^{31}$

The improved cardio-respiratory response observed in the HYP group could be due to the greater relative intensity of the same workload than in NOR group. 
The decrease in the post-exercise heart rate is typically exponential. ${ }^{32}$

The decrease during the first minute is marked by variables such as parasympathetic blockade. In contrast, in the second phase (after the first minute), it is believed to be mediated by the gradual withdrawal of sympathetic activity and steady plasma clearance of metabolites (epinephrine, lactate, $\mathrm{H}^{+}$, etc.) caused by the high intensity exercise. ${ }^{33}$ On the basis of this rationale, the training protocol significantly changed the decline HRR HYP group versus the NOR group during post-training. This observation could be attributable to distinct sympathetic activity and increased removal of plasma metabolites, as reflected in the HYP group by an improved HRRI over time. Thus, plasma metabolite clearance and sympathetic activity was altered after twelve sessions of intermittent hypoxia.

Assessment of HRR from maximal exercise in the first few minutes after exercise is a valid estimate of the risk of sudden death. Given the increasing numbers of sudden death cases, this approach provides a useful non-invasive tool to assess the health and fitness of subjects. ${ }^{8}$

Several protocols have been reported in order to measure perceived exertion closely related to the physiological effects of training. In fact, it has been shown that physiological factors have a greater influence than psychological ones on the perception of fatigue, because training changes the way stress is perceived. ${ }^{34}$

In our case, the subjective perception of exertion was higher in the HYP group (unpublished data), thereby supporting the hypothesis described above. Since it is not possible to assess the effect of self-suggestion or placebo and a double-blind experimental design is also impossible (subjects know if they are training into the chamber or not), we can only compare two different groups. ${ }^{27}$

An important negative effect of training in altitude on certain sport modalities is the limitation on workload intensity (relative to sea level) and the difficulty of maintaining high intensities of motor execution. Both factors can prevent the achievement of valid specific workouts in hypoxia. It has been argued that the difficulty involved in motor execution, at real or simulated altitude, impairs the efficiency of the motor coordination needed for the implementation of specific technical measures (stride, stroke, cadence, etc.) because of the difficulty of maintaining the same intensities as at sea level. ${ }^{35}$ In our case, the execution of squat jumps were technically maintained and performed equally by both groups.

We conclude that a high intensity (strength/endurance) physical training programme (4 weeks, 3 days per week) performed in hypoxia improves the HRRI in first 3 min after exercise has ended compared to the same training at sea level. Our training protocols in hypoxia have allowed a better recovery from maximal stimulation and also have improved fitness and performance opportunities. In addition, individual subjective perception of effort (higher in HYP than in NOR) supports the hypothesis of an increased relative intensity of effort in the group training at simulated altitude.

The physiological and psychological effects of training in a hypobaric chamber could explain the enhanced improvement in the performance of the HYP group compared with same training in NOR group. Also, the possible increase in the relative intensity of the effort performed under hypoxia should be taken into account to objectively evaluate the improvement in performance. We consider that our findings may contribute to new applications in the field of high performance training for athletes.

\section{Presentation}

The heart rate data in the recovery phase were presented at the VI International Congress of the Spanish Association of Sports Science in Elche, on October 6, 2010. There was a poster presentation of $10 \mathrm{~min}$, with open questions, from 11 to $11.15 \mathrm{am}$.

\section{Conflicts of interest}

The authors have no conflicts of interest to declare.

\section{Acknowledgements}

This study would not have been possible without the generous collaboration of all the volunteers. The authors also thank Dr. Casimiro Javierre (Faculty of Medicine, UB) and Rubén Martínez (HUB) for their help and medical supervision. The authors also thank Mr. Ignacio Montoya (ZR Barcinova) and Mr. Santiago Blázquez (Fibre Medic) for their cooperation and for the loan of material.

\section{References}

1. Calderon FJ, Cruz E, Montoya J. Estudio comparado de la recuperación de la frecuencia cardíaca en deportistas de fondo: triatletas, atletas, nadadores y ciclistas. Área de fisiología del ejercicio-Rendimiento deportivo, 261. I Congreso de la Asociación deportiva de Ciencias del deporte. Universidad de Extremadura.

2. Darr K, Basset B, Morgan B, Thomas D. Effects of age and training status on heart rate recovery after peak exercise. Am J Physiol Heart Circ Physiol. 1988;254:H340-3.

3. Calderón Montero FJ, Brita Paja JL, González C, Machota V. Estudio de la recuperación de la frecuencia cardíaca en deportistas de élite. Revista Española de la Medicina de la Educación Física y el Deporte. 1997;6:101-5.

4. Savin WM, Davidson DM, Haskell WL. Autonomic contribution to heart rate recovery from exercise in humans. J Appl Physiology. 1982;53:1572-6.

5. Imai $\mathrm{K}$, Sato $\mathrm{H}$, Hori $\mathrm{M}$. Vagally mediated heart rate recovery after exercise is accelerated in athletes but blunted in patients with chronic heart failure. J Am Coll Cardiol. 1994;24:1529-35.

6. Arai Y, Saul JP, Albrecht P. Modulation of cardiac autonomic activity during and immediately after exercise. Am J Physiol. 1989;256:H132-41.

7. Cole C, Blackstone E, Pashkow F, Snader C, Lauer M. HRR immediately after exercise as a predictor of mortality. Hellenic Endocr Soc. 1999;341:1351-7.

8. Jouven X, Empana JP, Schwartz P, Desnos M, Courbon D, Ducimetiere $P$. Heart rate recovery during exercise as a predictor of sudden death. N Engl J Med. 2005;352:1951-8.

9. Levine BD. Intermittent hypoxic training: fact and fancy. High Alt Med Biol. 2002;3:177-93.

10. Martino M, Myers K, Bishop P. Effects of 21 days training at altitude on sea-level anaerobic performance in competitive swimmers. Med Sci Sports Exerc. 1996;27:S5. 
11. Weston AR, Mbambo Z, Myburgh KH. Running economy of African and Caucasian distance runners. Med Sci Sports Exerc. 2000;32:1130-4.

12. Frisancho AR, Martinez C, Velasquez T, Sanchez J, Montoye H. Influence of developmental adaptation on aerobic capacity at high altitude. J Appl Physiol. 1973;34:176-80.

13. Kollias J, Powers SK, Thompson D. Work capacity of longtime residents and newcomers to altitude. J Appl Physiology. 1968;64:1486-92.

14. Bayley, Davies. Physiological implications of altitude training for endurance performance at sea level: a review. Br J Sports Med. 1997;31:183-90.

15. Hendriksen IJ, Meeuwsen T. The effect of intermittent training in hypobaric on sea level a cross over study in humans. Eur J Appl Physiol. 2003;88 4-5:396-403.

16. Ogida F, Tobata T. The effects of high-intensity intermittent training under a hypobaric hypoxia condition on anaerobic capacity and maximal oxygen uptake. In: Keskinen KL, Komi PV, Hollander AP, editors. Biomechanics and Medicine of Swimming VIII. Jyvaskyla, Finland: Gummerus Printing; 1999. p. 423-7.

17. Stray-Gundersen J, Chapman RF, Levine B. "Living high, training low" altitude training improves sea level performance in male and female elite runners. J Appl Physiol. 2001;91:1113-20.

18. Burtscher $M$, Nachbauer W, Baumgartl P, Philadelphy $M$. Benefits of training at moderate altitude versus sea level training in amateur runners. Eur J Appl Physiol Occup Physiol. 1996;74:558-63.

19. Levine BD, Stray-Gundersen J. "Living high-training low": effect of moderate-altitude acclimatization with low-altitude training on performance. J Appl Physiol. 1997;83:102-12.

20. Brugniaux JV, Schmitt L, Robach P, Nicolet G, Fouillot JP, Moutereau S, et al. Eighteen days of "living high, training low" stimulate erythropoiesis and enhance aerobic performance in elite middle-distance runners. J Appl physiol. 2006;100:203-11.

21. Bonnetti DL, Hopkins WG, Kilding AE. High-intensity kayak performance after adaptation to intermittent hypoxia. Int J Sports Physiol Perform. 2006;1:246-60.

22. Gore CJ, Hahn AG, Aughey RJ, Martin DT, Ashenden MJ, Clark SA, et al. Live high:train low increases muscle buffering capacity and submaximal cycling efficiency. Acta Physiol Scand. 2001;173:275-86.

23. Bosco C, Luhtawen P, Komi PV. A simple method for measurement of mechanical power in jumping. Eur J Appl Physiol. 1983;50:273-82.

24. Bosco C, Komi PV, Thyhany G, Feleke G, Apor P. Mechanical power test and fibre composition of human leg extensor muscles. Eur J Appl Physiol. 1983;51:129-35.

25. Verhoshansky Y. Teoría y Metodología del entrenamiento deportivo. Ed. Paidotribo; 2001.

26. Moras G, Rodríguez-Jimenez S, Busquets A, Tous-Fajardo J, Pozzo M, Mujika I. A Metronome for controlling the mean velocity during the bench press exercise. J Strength Cond Res. 2009;23:926-31.

27. Beedie CJ. Placebo effects in competitive sports: qualitative data. J Sports Sci Med. 2007;6:21-8.

28. Heistad DD, Abboud FM. Circulatory adjustments to hypoxia. Circulation. 1980;61:463-70.

29. Bärtsch P, Gibbs SR. Effect of altitude on the heart and the lungs. Circulation. 2007;116:2191-202.

30. Perini R, Orizio C, Comande A, Castellano M, Beschi M, Veicsteinas A. Plasma norepinephrine and heart rate dynamics during recovery from submaximal exercise in man. Eur $\mathrm{J}$ Appl Physiol Occup Physiol. 1989;58:879-83.

31. Buchheit M, Papelier $Y$, Laursen P, Ahmaidi S. Noninvasive assessment of cardiac parasympathic function: postexercise heart rate or heart rate variability? Am J Physiol Heart Circ Physiol. 2007;293:H8-10.

32. Noakes TD. Physiological models to understand exercise fatigue and the adaptations that predict or enhance athletic performance. Scand J Med Sci Sports. 2000;10:123-40.

33. Platonov V. La adaptación en el deporte. Barcelona: Paidotribo; 1991.

34. Borg G, Borg E. A new generation of scaling methods: level-anchored ratio scaling. Psychologica. 2001;28: 15-45.

35. Amann M, Pegelow DF, Jacques AJ, Dempsey JA. Inspiratory muscle work in acute hipoxia influences locomotor muscle fatigue and exercise performance of healthy humans. Am J Physiol Regul Integr Comp Physiol. 2007;293: R2036-45. 